\title{
COMPARAÇÃO DO DESEMPENHO ECONÔMICO E DE MERCADO DAS EMPRESAS: O CASO DAS COMPANHIAS CLASSIFICADAS NOS NÍVEIS DE GOVERNANÇA CORPORATIVA DA BOVESPA
}

\author{
Rosilene Marcon ${ }^{1}$ \\ Everson Manoel de Souza ${ }^{2}$
}

\begin{abstract}
Resumo: 0 objetivo principal deste estudo foi investigar a relação entre 0 desempenho econômico e de mercado das companhias de capital aberto no mercado de ações do Brasil e sua inclusão nos níveis de governança corporativa propostos pela BOVESPA. Destaca-se o período de estudo compreendido entre os anos de 1999 e 2004, sendo, nessa faixa de tempo, coletados indicadores de desempenho ROE, ROA e P/VPA - os quais serviram como demonstrativos de viabilização para mensuração do comportamento econômico e de mercado das empresas listadas nos níveis de governança corporativa. Os resultados da pesquisa denotam o bom desempenho do indicador P/VPA que obteve melhor performance perante os demais indicadores estudados.
\end{abstract}

Palavras-Chave: Desempenho econômico. Bovespa. Governança corporativa.

\section{INTRODUÇÃO}

A imagem institucional das empresas pode tornar-se um ponto forte e favorável a sua relação com os stakeholders - destacados por Silveira (2004) como "todos os públicos envolvidos com a companhia, como clientes, empregados, fornecedores etc." - podendo criar uma boa política de governança corporativa e melhorar a imagem institucional que, segundo Barich; Srinivasan (1993 apud MARCON, 2003), consiste em um diferencial de extrema importância para o destaque positivo da empresa junto ao mercado consumidor.

Srour (2000) corrobora as afirmativas supracitadas alegando que a imagem que as empresas buscam passar aos clientes é, justamente, a de empresas éticas, pois estas entendem que pode ser determinante - para os stakeholders - o fato de elas subordinarem suas atividades a uma prévia análise ética, além de trabalharem seriamente em prol da responsabilidade social, disseminando a imagem de empresas moralmente inatacáveis.

Dessa forma, as empresas socialmente corretas podem "usar" a transparência administrativa em prol de aumento de sua valorização no mercado acionário, podendo assim elevar o preço de cotação de suas ações, fator este que proporcionará um maior ganho aos acionistas, tornando a companhia mais atrativa inclusive a potenciais investimentos.

É importante que as empresas se conscientizem de que a prática da boa governança corporativa repercute em boas relações com os stakeholders. Para tanto, muitas pesquisas estão sendo realizadas com intuito de aprimorar e introduzir o conceito de governança corporativa no meio organizacional e acadêmico, objetivando a expansão do significado do tema, tornando-o cada vez mais atrativo a pesquisas de foro científico.

\footnotetext{
1 Programa de Pós-Graduação em Administração e Turismo, UNIVALI, Itajaí, SC. E-mail: rmarcon @univali.br

2 Graduação em Administração, UNIVALI, Itajaí, SC. E-mail: eversonms@yahoo.com.br
} 
Os administradores das empresas ligadas à governança corporativa preocupam-se com a divulgação dos resultados da empresa, transmitindo-os de forma clara aos acionistas para que estes tenham a noção precisa da rentabilidade de seus investimentos. Além disso, deve haver a preocupação com os acionistas e credores quando as tomadas de decisão dizem respeito à aplicação dos recursos provenientes de seus lucros, os quais devem ser expostos de forma transparente, sabendo destinar investimentos e dividendos.

Com o objetivo de traçar um comparativo entre o desempenho econômico e de mercado das empresas inseridas nos níveis de governança corporativa, propostos pela BOVESPA, e sua classificação em tais níveis, esta pesquisa buscou associar boas práticas corporativas ao posicionamento das empresas no mercado acionário, verificando, dessa forma, se essa prática proporciona objetivos realmente relevantes para as companhias de capital aberto cujas ações são negociadas na BOVESPA, enfatizado a análise dos indicadores de rentabilidade e tendo em vista que a finalidade principal das organizações é a maximização da riqueza dos acionistas.

\section{GOVERNANÇA CORPORATIVA: CONCEITOS, NÍVEIS E MODELOS}

A expressão "Governança Corporativa" ainda não se tornou totalmente compreendida no mercado econômico mundial, porém, sua aplicação prática é reconhecida como sendo de fundamental importância para o crescimento sólido da economia mundial. Essa expressão teve origem no ano de 1991, o primeiro código de melhores práticas de governança corporativa foi elaborado em 1992 e, em 1995, surgiu o primeiro livro "Corporate Governance", escrito por R. Monks e N. Minow (ANDRADE; ROSSETTI, 2004).

Entende-se que é cada vez mais importante o esclarecimento desse tema. Carlsson (2001 apud Silveira, 2004) sugere que o século XIX caracterizou-se como a era dos empreendedores, 0 século XX como a era do gerenciamento e o século atual, o XXI, como a era da governança corporativa. Nessa linha de raciocínio, Steinberg (2003) acrescenta que, além de proteger os investidores, a adoção da política da boa governança tende a valorizar as empresas que a praticam, pois os investidores entendem que o retorno de suas aplicações implicarão ganhos generalizados, podendo contribuir para o crescimento mútuo, aumentando o nível de satisfação de todos os stakeholders relacionados à empresa.

Atualmente, tornou-se impossível imaginar o desenvolvimento sustentável de um mercado de ações sem relacioná-lo a uma boa política de governança corporativa. O fortalecimento do mercado de ações de um país está atrelado à conduta das empresas perante os seus acionistas. Essa conduta deve estar fundamentada em princípios que garantam um tratamento equinânime a todos os investidores, independentemente de seu porte e visando a valorização da corporação e do produto/ação oferecido por esta. Portanto, questões que envolvam crescimento e fortalecimento do mercado acionário envolvem o exercício da governança corporativa. A essa afirmativa soma-se 0 fato de que estudos já comprovam que os mercados de ações mais desenvolvidos do mundo atribuem maior grau de importância às empresas que promovem maior disseminação de suas ações (RODRIGUEZ, 2005).

No intuito de explicar o tema, IBGC (2005) destaca a governança corporativa como sendo um "sistema" que visa monitorar as sociedades, aprimorando as relações entre acionistas/cotistas, conselho de administração, auditoria independente e conselho fiscal. Nesse contexto, pode-se considerar que a governança corporativa, quando praticada de forma correta, tem como objetivo primordial a maximização do valor da sociedade, a facilitação da captação de recursos e a contribuição para que a organização obtenha "longa vida". 
Seguindo a mesma linha de raciocínio, Rabelo; Silveira (1999) e Lethbridge (2004) também definem a governança corporativa como um "sistema" em que os acionistas exercem seu direito legal sobre o controle das corporações. Os autores acrescentam que a construção desse sistema está baseada na formação de um conjunto de instituições, regido por regulamentos cujo intuito é garantir a boa relação entre as empresas e seus acionistas, considerando o modelo administrativo de cada companhia envolvida. Dessa forma, entende-se que o sistema denominado governança corporativa está amplamente ligado à estrutura de propriedade e monitoramento das companhias, bem como seu vínculo ao mercado acionário.

Considerando, ainda, a inserção no conceito que aborda a governança corporativa como sendo um sistema, CVM (2002) destaca que esse sistema deve possuir um conjunto de procedimentos cuja finalidade é garantir a inserção de alguns benefícios - otimizar o desempenho das companhias participantes da bolsa de valores; garantir o aumento das ações das companhias através da boa imagem corporativa; reduzir o custo de capital; facilitar o aumento da viabilidade de obtenção de recursos no mercado de capitais; garantir aos stakeholders os direitos sobre os ativos da companhia, protegendo-os contra acionistas controladores, que têm poder de influenciar decisões em nome da companhia - com o intuito de promover o desenvolvimento sustentável do mercado de ações e formar uma excelente imagem do mesmo perante os agentes envolvidos.

Ao abordar a governança corporativa num contexto mais direcionado aos acionistas, Siffert Filho (2002) cita que sua prática representa uma maior interação entre os administradores e proprietários de determinada corporação, fazendo com que as decisões tomadas respeitem os interesses de ambos. Os acionistas controladores, dessa forma, apóiam-se na prática da governança corporativa como um sistema através do qual exercerão controle e monitorarão a atuação da companhia.

Contudo, o estudo realizado por Lima; Terra (2004) - que relaciona o grau de influência das divulgações de informações financeiras realizadas por empresas não participantes dos níveis de governança ao de empresas diferenciadas pela participação em tais níveis, revelando a existência de reações diferenciadas nos investidores quanto à sinalização de prática de governança corporativa demonstra que esse "monitoramento" da atuação da companhia dependerá diretamente do ambiente institucional em que esta inserida e será delineado pelo sistema de governança corporativa praticado pela empresa. A partir dessas considerações, chega-se ao consenso de que a garantia do relacionamento correto entre acionistas controladores; minoritários; credores e gestores promove a valorização da companhia e o retorno aos acionistas sintetiza-se no conceito de governança corporativa voltado ao âmbito societário

Sob a visão de Rodriguez (2003), a governança corporativa representa a reunião de regras e normas, as quais devem ser adotadas e seguidas pelas companhias de capital aberto, com o intuito de promover tratamento igualitário ao seu conjunto de investidores, primando pela igualdade e respeito aos minoritários, praticando disclosure - transparência - e buscando a valorização da companhia perante 0 mercado acionário. $O$ autor acrescenta que o fortalecimento do mercado de capitais está diretamente relacionado à prática de uma política de governança corporativa bem fundamentada, ou seja, independente do porte dos acionistas da companhia.

A aplicação da política de governança baseia-se no direito dos acionistas de saberem, com máxima transparência, o destino dos recursos por eles empregados junto à corporação. Para tanto, fazse necessária aplicação de normas que regulamentem o mercado de capitais no país, oferecendo maiores garantias aos investidores, mesmo que estes possuam poucas ações. É nesse sentido que 0 Instituto Brasileiro de Governança Corporativa (IBGC) criou o código das melhores práticas de governança corporativa que - dividido em propriedade; conselho de administração; gestão; auditoria; fiscalização e ética - visa a total transparência e igualdade de direitos entre todos os acionistas 
majoritários e minoritários, orientando a correta prestação de contas em todos os níveis de estrutura da organização (STEINBERG et al., 2003).

Conforme Silveira (2004), a governança corporativa pode ser influenciada pela estrutura de propriedade existente na organização. As empresas maiores e com melhor desempenho financeiro são as que apresentam, em média, melhor governança corporativa. Ao confrontar-se a afirmação anterior com a conclusão de Okimura; Silveira; Rocha (2004), que defendem que "a concentração média de votos dos acionistas controladores é alta nas empresas brasileiras", chegando a apresentar uma média geral de 76,1\%, pode-se concluir que a introdução dos princípios fundamentais da boa governança corporativa - citados por Villares (2003 apud STEINBERG et al, 2003) e IBGC (2005) como sendo a transparência, equidade, prestação de contas, cumprimento de leis e ética - ainda encontra dificuldades para vencer a "barreira" da concentração de capital votante nas companhias brasileiras.

Nesse sentido, o estudo, realizado por Leal; Silva; Valadares (2002), a respeito da estrutura de controle das companhias brasileiras de capital aberto, demonstra a baixa existência de propriedade difusa - grande número de pequenos acionistas - nas companhias brasileiras com ações negociadas no pregão da BOVESPA, classificando essa característica como negativa para o fortalecimento dos mercados de ações e, conseqüentemente, para a governança corporativa. Outro fator alarmante para a estrutura de propriedade das companhias brasileiras diz respeito aos casos cuja existência de um acionista controlador não é detectada e, mesmo assim, o acionista majoritário detém uma parcela significativa das ações ordinárias, caracterizadas pela obtenção de direito ao voto, podendo, neste caso, o controle da companhia estar nas mãos dos três maiores acionistas. Número considerado baixo para os padrões mais aprofundados de governança corporativa.

Perobelli et al (2005) baseiam seu estudo a respeito da governança corporativa na hipótese de que a qualidade da governança corporativa exercida pela empresa emissora de ações é um fator influenciador da sua estrutura de capital. Dessa forma, destacam a estrutura de capital como sendo um importante instrumento de governança corporativa e captação de recursos. Tal destaque é enfatizado pela idéia de que companhias caracterizadas por pulverização acionária possuem maior qualidade de governança corporativa com relação a empresas com alto grau de concentração acionária. Dessa forma, a análise desses fatos conclui que as companhias posicionadas como defensoras das práticas de governança e com alto grau de pulverização estão mais cotadas para a contratação de recursos, sejam estes próprios ou de terceiros.

Ainda considerando os princípios básicos para o exercício efetivo da governança corporativa e corroborando as afirmativas de Steinberg (2003) e IBGC (2005), citadas anteriormente, dá-se destaque à formulação proposta por Lustosa (2002), que cita as entidades participantes do sistema da governança corporativa - o conselho administrativo (formado por conselheiros independentes); a diretoria da companhia; os auditores externos (independentes) e os stakeholders - e define alguns princípios básicos a serem seguidos pelas empresas que desejam participar do círculo de governança, destacando-os: Compliance - cumprimento das normas e procedimentos aplicáveis à boa política de governança corporativa; Disclosure - transparência nas informações prestadas; Fairness - aplicação de justiça com os acionistas minoritários; Accuntability - prestação responsável de contas.

Aos princípios acima citados, pode-se somar o principio denominado "enforcement", destacado por Cicogna; Valle; Toneto Jr. (2005) como sendo o grau de eficiência no cumprimento de leis e regras, estando diretamente ligado à eficácia do sistema judiciário. 0 "enforcement" é considerado de extrema importância para o desenvolvimento financeiro e econômico de uma nação, podendo, portanto, ser de fundamental importância para o desenvolvimento de regras que irão reger o bom funcionamento do mercado de capitais e, conseqüentemente, as práticas ligadas à governança corporativa.

No que diz respeito à influência de alguns agentes sobre a governança corporativa, também é preciso analisar sobre quais fatores esta pode não acarretar mudanças. Dessa forma, Rogers; Ribeiro (2004) - defensores da hipótese de que a prática da governança corporativa, por parte das empresas 
que negociam ações em bolsa, é essencial ao crescimento, aprimoramento e confiabilidade do mercado de ações brasileiro - citam que a adoção das práticas de governança não altera a estrutura de propriedade concentrada no mercado, assim como não altera o fato de os papéis lançados pelas empresas praticantes da governança corporativa concorrerem com papéis considerados de grande rentabilidade, tornando aberta a competição entre empresas praticantes ou não dos princípios das melhores práticas de governança.

Contudo, a prática da governança, conforme a pesquisa de Schleifer; Vishni (1996 apud LAMB, 2002), não é motivada simplesmente pela livre competição. A criação de mecanismos de governança está inserida em um contexto que conta com a presença de instrumentos legais, institucionais e econômicos, os quais podem evoluir de acordo com as práticas adotadas pelas empresas. Com esse estudo, Lamb (2002) visava apresentar a governança corporativa como sendo um conjunto formado por empresas e regras, em que as últimas determinam os caminhos a serem seguidos para a aplicação correta dos recursos alocados à organização e administrados pelos seus acionistas controladores e/ou gestores, visando à redução das onerosidades provindas do custo de capital.

Rogers; Ribeiro (2003), citados pelo estudo da relação existente entre risco Brasil e as práticas de governança corporativa, destacam que os sistemas de governança foram desenvolvidos com base nas particularidades culturais, econômicas e históricas de cada país, caracterizando, dessa forma, as diferentes peculiaridades existentes nos formatos de cada mercado de ações e suas regras de conduta. Os autores destacam, ainda, o modelo anglo-saxão de governança corporativa - utilizado nos Estados Unidos e Inglaterra - como sendo o mais completo e adequado do mundo, tornando-se um dos principais protagonistas da evolução do mercado de ações inglês.

Em perspectiva similar, Silveira (2002) cita que a conduta adotada pelas empresas no seu sistema de governança corporativa é proporcional à estrutura institucional que envolve a empresa, caracterizando, portanto, a importância dos agentes econômicos - governo, sociedade - no mercado acionário de uma nação. Os autores afirmam que o modelo de governança corporativa praticado nos Estados Unidos e no Reino Unido baseia-se na forte proteção destinada aos acionistas minoritários. Assim sendo, é conclusivo o fato de que o Estado, através da definição dos sistemas financeiro e legal e do grau de proteção aos investidores, modela a formação do mercado de capitais local, influenciando o modelo de governança das empresas. Dessa forma, os países apresentam diferenças significativas entre os sistemas de governança corporativa das suas empresas.

Análises realizadas por Silveira (2004) e Hallqvist (2003) definem que, embora a história da governança corporativa esteja fortemente atrelada aos movimentos ocorridos nos Estados Unidos da América, onde 0 mercado de capitais teve atuação determinante na disseminação dos padrões de governança para outros mercados, várias outras nações desempenharam papel importante nesse sentido, todas motivadas pela busca de um mercado acionário com maior transparência e equidade. Essas análises apontam alguns mercados cuja atuação e conduta ajudam a promover uma política de governança corporativa mais atuante perante as companhias de capital aberto em seus respectivos territórios: no Reino Unido, Japão, Alemanha, França e nos Estados Unidos.

A questão do desenvolvimento e introdução da governança corporativa no mundo foi também estudada por Canuto (2000), que destacou as ações das principais economias mundiais - EUA, Inglaterra, Alemanha e Japão - em aplicar políticas cujo interesse prioritário fosse a criação de mecanismos, através dos quais os investidores pudessem exercer e monitorar o comando das companhias em que seus investimentos encontravam-se aplicados, bem como a conduta de seus mercados acionários quanto aos tipos de financiamentos e as características das fontes geradoras de recursos.

Destaca-se no estudo do grupo dos países mais desenvolvidos no quesito mercado de ações, a pesquisa realizada por Lethbridge (2004), que identificou dois modelos clássicos de governança corporativa, classificados por ele como sendo: o modelo anglo-saxão, originário dos Estados Unidos e 
da Inglaterra, e o modelo nipo-germânico, predominante no Japão e Alemanha, estendendo-se também a maioria dos países da Europa continental. Explicando os dois modelos citados e tomando a concentração acionária como elemento de comparação, percebe-se que há maior pulverização no modelo de governança corporativa anglo-saxão. Essa afirmação baseia-se na pesquisa de Lethbridge (2004), que comprova que os cinco maiores acionistas possuem menos do que $10 \%$ do capital de uma companhia. Em contraste ao modelo anglo-saxão, o nipo-germânico, ao ser estudado conforme sua concentração, apresentou uma média de propriedade concentrada na Alemanha e Japão de $40 \%$ e $25 \%$, respectivamente.

No Brasil, a governança corporativa teve início em 1994, quando começaram as discussões em torno da criação de um órgão que definisse padrões a serem adotados pelos conselhos de administração no intuito de reduzir suas deficiências. Com esse objetivo, em 27 de novembro de 1995, foi fundado o Instituto Brasileiro de Conselheiros de Administração (IBCA) (HALLQVIST, 2003). No entanto, conforme citado por IBGC (2005), o IBCA sentiu a necessidade de ampliar suas atividades, não focando somente conselhos de administração, mas abrangendo também a propriedade, a diretoria, o conselho fiscal e a auditoria independente. Em 1999 passou a denominar-se Instituto Brasileiro de Governança Corporativa (IBGC), o qual não possui fins lucrativos.

A partir dos anos 90, conforme citam Andrade; Rossetti (2004), houve um enriquecimento dos conselhos administrativos no Brasil, influenciado pelas mudanças internas e externas, as quais se refletiram nas empresas nacionais. Dentre as mudanças ocorridas, destacam-se: privatizações, sucessões, fusões, abertura da economia, criação do IBGC, surgimento de códigos das melhores práticas de governança corporativa.

Ao tratar mudanças consideradas necessárias à evolução da governança no Brasil, Srour (2002) defende que o mercado de ações brasileiro prima pela necessidade de uma Lei de S.A menos maleável, que ajude a promover maior proteção aos interesses dos acionistas minoritários. Os avanços desta lei não são suficientes para garantir as boas práticas de governança corporativa no mercado de capitais brasileiro, sendo mais indicado, para o momento, a assinatura de contratos de característica privada para a garantia desse processo. Contudo, ainda que considerada pouco rígida para garantir a evolução das práticas de governança corporativa no mercado de ações, a lei n. 10.303, de 31 de outubro de 2001 é destacada por Vieira; Mendes (2004) como um importante marco que - somado a um conjunto de determinações anunciadas por órgãos reguladores, citados a BOVESPA, Comissão de Valores Mobiliários e Banco Central do Brasil - pode promover o crescimento sustentável do mercado de ações brasileiro e a implantação de regras claras para o estabelecimento das práticas de governança corporativa.

O histórico da evolução da governança corporativa nos países cujo mercado de ações ainda apresenta falhas de conduta e seu grau de amplitude financeira está posicionado em baixos patamares - caso do Brasil nos anos 90 - demonstra que as regras de governança, necessárias ao desenvolvimento de suas companhias, são importadas dos países com maior tradição na aplicação de práticas de boa conduta com relação a seus investidores (acionistas). Contudo, de nada adianta 0 aprendizado obtido junto aos países mais desenvolvidos se a estrutura utilizada na aplicação do enforcement não estiver fundamentada em alicerces firmes, bem definidos quanto a sua importância no aprimoramento do mercado de capitais e na prática das regras que dizem respeito à governança corporativa (CICOGNA; VALLE; TONETO JR., 2005).

De acordo com Lethbridge (2004), o fortalecimento das companhias brasileiras no sistema de governança corporativa pode estar ligado ao fortalecimento do poder dos investidores através do aumento no número de companhias brasileiras expostas aos mercados de capitais, com destaque para o norte-americano, comprovado pelas 44 empresas brasileiras que lançaram ADRs na bolsa de Nova Yorque. Isso comprova o crescimento das companhias brasileiras no foco da governança, tendo em 
vista o fato de alguns dos lançamentos de ADRs terem sido realizados no nível 3, o qual exige um padrão extremamente rigoroso nos demonstrativos contábeis.

Conforme BOVESPA (2005), grande parte das empresas brasileiras, que negociam suas ações no mercado acionário, está buscando inserção nos níveis de governança e primando pelo cumprimento dos princípios básicos de boas regras de governança corporativa, assumindo que essa prática trará ganhos significativos a seus investidores, principalmente em relação à transparência administrativa. 0 mercado acionário brasileiro dá demonstrações claras de que a adesão aos níveis diferenciados de governança corporativa da BOVESPA destaca a busca das empresas participantes pela melhoria na relação com acionistas, além de proporcionar aumento do potencial de valorização dos seus ativos.

A explicação básica e direta sobre a decisão de implantação do Novo Mercado e de níveis diferenciados de governança corporativa parte da identificação, por parte da Bolsa de Valores de São Paulo, da necessidade de proporcionar aos investidores e companhias um ambiente de negociação em que pairasse transparência, tratamento igualitário, prestação de contas, responsabilidade corporativa e que, além disso, pudesse proporcionar o aumento do interesse dos investidores e a valorização das companhias, tanto no âmbito econômico quanto na melhora de sua imagem perante os stakeholders.

Os níveis diferenciados de governança corporativa conhecidos atualmente no mercado de ações brasileiro e destacados por Steinberg et al (2003), foram criados pela Bolsa de Valores de São Paulo (BOVESPA), em dezembro de 2000, com 0 intuito de desenvolver, no mercado de capitais brasileiro, uma estrutura bem elaborada de negociação, a qual estimulasse, além do interesse dos investidores, a valorização das companhias, partindo do conhecimento de países com grande experiência no setor, os quais alegam que a adesão às boas práticas de governança corporativa demonstra maior grau de compromisso por parte das companhias junto ao mercado e seus investidores.

Dessa forma, a exemplo dos países cujos mercados acionários possuem grande índice de desenvolvimento, a BOVESPA vem tomando a iniciativa de formar níveis de governança, desenvolvendo uma listagem na qual serão inscritas as empresas interessadas em: aumentar voluntariamente seu nível de comprometimento, adotar práticas de governança corporativa e transparência além do mínimo exigido pela Lei Federal n 6404/1976, que regulamenta os padrões contábeis a serem estabelecidos para a prestação de informações financeiras das companhias participantes do mercado de capitais do Brasil. Essa listagem - cujo objetivo garantir maior grau de segurança ao público investidor e a melhora na qualidade da apresentação das informações financeiras - está dividida em três níveis de governança corporativa, diferenciados entre si pelos padrões mínimos de exigências proposto pela BOVESPA a sua adesão (CICOGNA; VALE; TONETO JR., 2005).

No estudo relacionando à migração das empresas de capital aberto com papéis negociados na BOVESPA, Carvalho (2003) alega que a migração nos níveis de governança tem impacto direto sobre a valorização das ações, bem como sobre o aumento do volume de negociações, apresentando significativa redução na exposição da empresa a fatores macroeconômicos. $O$ autor conclui que as ações das empresas que aderiram às regras de governança corporativa da BOVESPA apresentaram incremento em sua liquidez. Além disso, o desenvolvimento do mercado de capitais tem relação direta com a adoção das boas práticas de governança corporativa. Esse fato baseia-se na condição de que, para alcançar o desenvolvimento do mercado de ações, é preciso aumentar os direitos dos acionistas minoritários. Assim sendo, quando essa condição é atingida, há um aumento na satisfação dos investidores que detêm um número menor de ações, tornando mais confiável a aplicação de recursos na companhia a qual a ação está vinculada. Dessa forma, pode-se entender que a busca pelos níveis mais elevados está diretamente relacionada ao grau de proteção que é dispensado aos investidores minoritários.

A BOVESPA possui 3 níveis diferenciados de governança corporativa que, de acordo com Oliveira; Silva (2004), visam destacar, entre as empresas negociadoras de ações no mercado, àquelas 
que assumem compromissos além dos estabelecidos pela legislação quanto à transparência e ao grau de governança corporativa. A inclusão da empresa em um dos níveis da BOVESPA - 1, 2 e Novo Mercado - exige algumas regras de adesão.

Para fazer parte do grupo das organizações classificadas no Nível 1 de governança corporativa, a empresa deve preencher aos seguintes requisitos: manutenção em circulação de uma parcela mínima de ações, representando $25 \%$ do capital; realização de ofertas públicas de colocação de ações por meio de mecanismos que favoreçam a dispersão do capital; melhoria nas informações prestadas trimestralmente, entre as quais a exigência de consolidação das demonstrações contábeis e de revisão especial de auditoria; informar negociações de ativos e derivativos de emissão da companhia por parte de acionistas controladores ou administradores da empresa; disponibilização de um calendário anual de eventos corporativos; apresentação das demonstrações do fluxo de caixa BOVESPA (2002).

Para fazer parte do grupo das organizações classificadas no nível 2 de governança da BOVESPA, as regras são ainda mais rígidas para oferecer maior proteção aos acionistas minoritários, devendo a empresa preencher aos seguintes requisitos: conselho de administração com mínimo de cinco membros e mandato unificado de um ano; disponibilização de balanço anual seguindo as normas do US GAAP ou IFRS; extensão para todos os acionistas detentores de ações ordinárias das 7 mesmas condições obtidas pelos controladores quando da venda do controle da companhia e de, no mínimo, 70\% desse valor para os detentores de ações preferenciais (tag along); direito de voto às ações preferenciais em matérias como transformação, incorporação, cisão, fusão e aprovação de contratos entre a companhia e empresas do mesmo grupo sempre que sejam deliberados em assembléia geral; adesão à Câmara de Arbitragem para resolução de conflitos societários BOVESPA (2002)

Existe ainda um terceiro nível de governança chamado de "Novo Mercado", estando à adesão da companhia a esse nível atrelada a uma série de obrigações além da já listadas nos níveis 1 e 2 . Em seu estudo, Andrade; Rosseti (2004) destacam o Novo Mercado como sendo um nível de governança especial, mais voltado às corporações que venham a abrir seu capital em ofertas públicas no valor mínimo de $\mathrm{R} \$ 10.000 .000,00$ (dez milhões de reais); companhias de capital aberto com mínimo de 500 acionistas e apenas ações ordinárias; companhias que possuam ações preferenciais, mas que possam ser convertidas em ordinárias. As condutas de governança exigidas no Novo Mercado são ainda mais rígidas que as exigidas pela legislação brasileira, compondo-se pelas mesmas exigidas no nível 2, somada as seguintes condições: apenas ações ordinárias, Tag along e divulgação de balanços de acordo com o padrão existente no mercado acionário norte-americano.

\section{METODOLOGIA}

Para realização deste estudo, foi desenvolvida pesquisa quantitativa. Os indicadores foram extraídos dos demonstrativos financeiros das empresas estudadas, encontrados junto à base ECONOMÁTICA® no período compreendido entre os anos de 1999 a 2004.

Para a determinação da amostra a ser estudada, fez-se necessária identificação das empresas participantes do sistema de listagem desenvolvido pela BOVESPA, separando-as das demais companhias com papéis negociados no mercado acionário brasileiro. Sendo assim, a amostra desta pesquisa foi composta por companhias praticantes da governança corporativa classificadas nos níveis 1, 2 ou Novo Mercado do mercado de ações. Foram consideradas, para efeito de coleta de dados e avaliação de desempenho, as respectivas datas em que cada empresa aderiu ao sistema de listagem.

Após identificação das companhias participantes do sistema de listagem da BOVESPA para 
práticas de governança corporativa nos níveis 1, 2 ou Novo Mercado, foi realizado levantamento dos indicadores necessários para a comparação do desempenho econômico e de mercado dessas empresas, tendo esses dados passado por um processo de tratamento estatístico e, posteriormente, sido expostos em gráficos ou planilhas, no intuito de facilitar sua interpretação, fornecendo um parecer concreto ao pesquisador a respeito de seus objetivos.

Contudo, esta análise não se limitou ao estudo das companhias listadas nos níveis de governança corporativa. Para obtenção de conclusões mais precisas junto ao mercado de ações quanto à adesão das companhias aos níveis de governança e às boas práticas corporativas, considerou-se também avaliar o desempenho das empresas praticantes das regras de governança junto às demais companhias não praticantes, mas com papéis negociados em bolsa no Brasil, de forma a tecer também comparações setoriais. Tal análise foi realizada de modo a separar todas as empresas que compõem a população em estudo - companhias integrantes de setores econômicos nos quais esteja inclusa alguma companhia listada em quaisquer dos níveis de governança corporativa conforme o setor econômico em que atuam. Através das médias dos indicadores selecionados (ROA, ROE e P/NPA) entre os anos de 1999 a 2004, foi realizada uma comparação entre o desempenho das empresas praticantes de governança corporativa e o setor nos quais tais empresas encontram-se inclusas. As análises dos resultados visam, portanto, demonstrar a comparação entre o desempenho das companhias individualmente, como também em relação ao seu setor econômico, incluindo empresas não-participantes, tomando por base de avaliação de desempenho o respectivo ano de adesão ao sistema de listagem proposto pela BOVESPA.

Os dados escolhidos para análise de desempenho referem-se aos indicadores de rentabilidade - Retorno sobre ativos (ROA) e Retorno sobre Patrimônio Líquido (ROE) utilizados para medir o desempenho econômico e para análise do desempenho de mercado, foi utilizado o indicador Preço/Valor Patrimonial (P/VPA). Dessa forma, a coleta dos dados junto à base Economática referente aos indicadores ROA, ROE e P/VPA foi realizada utilizando-se períodos anuais para cada indicador, tendo em vista que as empresas listadas nos níveis de governança corporativa possuem datas de adesão diferenciadas, as quais iniciam-se no ano de 2001, estando o período de avaliação de desempenho de cada companhia variando conforme sua data de adesão, obtida junto a BOVESPA.

Para realização dos estudos de desempenho e considerando as datas de adesão, foi desenvolvida metodologia de pesquisa que formou, para cada indicador, uma média calculada considerando os períodos (anos) anteriores à adesão, o ano da adesão e os períodos (anos) posteriores. Entretanto, algumas empresas constantes na amostra inicial foram excluídas por apresentarem data de adesão no ano 2004 ou posterior. Essa exclusão foi necessária devido à falta de dados comparativos futuros, já que esta pesquisa coletou informações até maio de 2005, quando muitas empresas ainda não tinham disponibilizado seus dados de desempenho, podendo fornecer somente informações anteriores à adesão. Também foram excluídas as empresas que não divulgaram seus relatórios financeiros no período estudado, fato determinante para obtenção de resultados mais precisos. A tabulação dos dados foi realizada de maneira a evitar que valores muito fora do padrão (outliers) participassem das avaliações, a fim de evitar distorções nos resultados obtidos.

Dando seqüência aos tratamentos estatísticos, seguindo um padrão conciso e igualitário a todos os indicadores e companhias estudados, foi calculado o desvio-padrão e excluídos todos os indicadores que apresentassem valores três vezes acima desse desvio, evitando-se distorções nos resultados.

Para tornar os resultados comparativos entre 0 antes e depois das adesões mais confiáveis, as médias calculadas para os indicadores foram submetidas à aplicação de "Teste $T$ " para dados pareados. Esse tipo de teste, segundo Barbetta (1999), envolve a comparação entre dois grupos de dados quantitativos, tomando por consideração suas médias e visando identificar se o resultado obtido após determinado evento é relevante ou não. Nesta pesquisa o evento analisado foi a migração das 
companhias para determinado Nível de Governança Corporativa. Dessa forma, para efetuar a aplicação do Teste $T$, duas hipóteses foram formuladas a partir dos valores médios obtidos junto aos cálculos realizados com os valores coletados para os indicadores nos períodos pré e pós adesão.

As hipóteses foram comparadas considerando nível de significância de $5 \%$, ou seja, se 0 resultado obtido através do teste for maior que 0,05 , ficará evidenciado que HO é verdadeira. Do contrário, se o resultado obtido da aplicação do teste denotar valor menor que o nível de significância $(\mathrm{a}=0,05), \mathrm{H} 0$ é rejeitada em favor de $\mathrm{H} 1$, demonstrando que há aumento real no desempenho das companhias após adesão aos níveis de governança.

\section{RESULTADOS}

Esta etapa da pesquisa consiste em demonstrar todas as análises realizadas, bem como apresentar os principais resultados obtidos através da avaliação dos indicadores pertencentes às companhias brasileiras participantes do sistema de governança corporativa proposto pela BOVESPA.

A avaliação final dos dados, discriminados por setor e indicador (ROE, ROA e P/NPA) - após montagem das planilhas que relacionam os setores estudados e as respectivas companhias integrantes desses setores - indica a quantidade de companhias, separadas por setor econômico, os quais apresentam aumento ou queda de sua performance econômica e de mercado, nas médias dos indicadores, após sua adesão aos níveis de governança corporativa, considerando somente as empresas e os setores que apresentam dados para compor a análise.(Tabela 1)

Tabela 1 - Performance das companhias após adesão (Aumento x Queda)

\begin{tabular}{l|cc|ccc|c}
\hline & \multicolumn{2}{|c|}{ ROA } & \multicolumn{3}{c|}{ ROE } & \multicolumn{2}{c}{ PVPA } \\
\hline \multicolumn{1}{c|}{ Setor } & Aumento & Queda & Aumento & Queda & Aumento & Queda \\
\hline Alimentos & 2 & 1 & 2 & 1 & 3 & 1 \\
Comércio & 1 & - & 1 & - & - & 1 \\
Construção & 1 & - & 1 & - & 1 & - \\
Energia Elétrica & 3 & - & 3 & - & 6 & - \\
Finanças e Seguros & - & 4 & 2 & 2 & - & 6 \\
Máquinas Industriais & 1 & - & 1 & - & 1 & - \\
Mineração & 1 & - & 1 & - & 2 & - \\
Outros & 2 & 3 & 2 & 2 & 2 & 3 \\
Papel e Celulose & 3 & 1 & 3 & 1 & 6 & - \\
Química & 1 & - & 1 & - & 2 & - \\
Siderurgia e Metalurgia & 3 & 1 & 3 & 1 & 6 & - \\
Telecomunicações & - & 2 & - & 2 & 3 & 1 \\
Têxtil & 3 & - & 3 & - & 5 & - \\
Transportes e Serviços & 1 & - & - & - & - & - \\
Veículos e Peças & 2 & - & 2 & - & 3 & - \\
\hline Total de companhias & $\mathbf{2 4}$ & $\mathbf{1 2}$ & $\mathbf{2 5}$ & $\mathbf{9}$ & $\mathbf{4 0}$ & $\mathbf{1 2}$ \\
\hline
\end{tabular}

Analisando a Tabela 1, com o objetivo de expor a relação entre a quantidade de companhias que apresentaram resultados positivos ou negativos após adesão, pôde-se concluir que, para a maioria das companhias (73\%), houve melhora na performance econômico-financeira e de mercado após sua inclusão em um dos níveis de governança corporativa, tendo o indicador P/VPA alcançando melhor resultado dentre os demais indicadores, já que 76,92\% das companhias que aderiram ao sistema de 
governança corporativa obtiveram crescimento em seu P/VPA. 73,53\% das companhias obtiveram crescimento no indicador ROE e 66,67\% no indicador ROA depois da adesão. Dessa forma, conclui-se que o ROA denota menor crescimento dentre os demais indicadores de adesão aos níveis de governança da BOVESPA.

Visto o crescimento comprovado para o indicador P/VPA e estando este diretamente ligado ao comportamento do preço da ação, ressalta-se que a conclusão obtida nesta pesquisa corrobora 0 estudo realizado por Carvalho (2003 apud CICOGNA; VALLE; TONETO JR, 2005), o qual afirma que a adesão aos níveis diferenciados de governança corporativa da BOVESPA promove um efeito positivo sobre os preços das ações das companhias no mercado de capitais, além de posicioná-las numa condição favorável à captação de recursos e diminuir possíveis restrições ao crédito, já que empresas praticantes de regras mais rígidas estão menos sujeitas a falta de garantias.

Conforme a Tabela 2, ao serem confrontadas as médias dos indicadores pertencentes às companhias listadas nos níveis de governança com as dos respectivos setores nos períodos anteriores e posteriores ao evento - migração para um dos níveis de governança -, identificou-se uma significativa vantagem das companhias em todos os indicadores estudados. Essa análise - identificando o número de companhias com nível de crescimento acima do setor - visa formar um "bloco" composto por empresas listadas nos níveis de governança e outro com as demais companhias somadas às listadas para, então, verificar separadamente 0 desempenho das empresas diferenciadas por prática de regras mais rígidas frente ao desempenho averiguado para o setor. Através dessa verificação, comprovou-se, através das médias calculadas, que, em $47,97 \%$ dos casos, as companhias alcançaram desempenho melhor frente ao setor econômico do qual participam. Destas, 44,44\% obtiveram superioridade em sua rentabilidade sobre ativos perante os setores estudados, 35,29\% superam os setores na avaliação da rentabilidade sobre patrimônio líquido e $58,49 \%$ no indicador de preço/valor patrimonial. Verifica-se, portanto, que o valor percentual de companhias listadas nos níveis de governança corporativa da BOVESPA e diferenciadas por práticas de regras mais rígidas que superaram seus respectivos setores em crescimento do P/VPA - 58,49\% - representa maioria, o que favorável a novas adesões.

\section{Tabela 2 - Companhias com crescimento acima do setor (Empresa x Setor)}

\begin{tabular}{|c|c|c|c|c|c|c|}
\hline \multirow[b]{3}{*}{ SETOR } & \multicolumn{6}{|c|}{ INDICADORES } \\
\hline & \multicolumn{2}{|c|}{ ROA } & \multicolumn{2}{|c|}{ ROE } & \multicolumn{2}{|c|}{ PVPA } \\
\hline & Empresas/setor & $\begin{array}{l}\text { Crescimento } \\
\text { acima do } \\
\text { setor }\end{array}$ & Empresas/setor & $\begin{array}{l}\text { Crescimento } \\
\text { acima do } \\
\text { setor }\end{array}$ & $\begin{array}{c}\text { Empresas/ } \\
\text { setor }\end{array}$ & $\begin{array}{l}\text { Crescimento } \\
\text { acima do } \\
\text { setor }\end{array}$ \\
\hline Alimentos & 3 & 1 & 3 & 2 & 4 & 3 \\
\hline Comércio & 1 & 1 & 1 & & 1 & - \\
\hline Construção & 1 & 1 & 1 & 1 & 1 & 1 \\
\hline Energia Elétrica & 3 & 1 & 3 & 2 & 6 & 5 \\
\hline Finanças e Seg. & 4 & 1 & 4 & 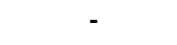 & 6 & - \\
\hline Máquinas Industriais & 1 & 1 & 1 & - & 1 & 1 \\
\hline Mineração & 1 & 1 & 1 & - & 2 & - \\
\hline Outros & 5 & 3 & 4 & - & 6 & 2 \\
\hline Papel e Celulose & 4 & 1 & 4 & 1 & 6 & 4 \\
\hline Química & 1 & 1 & 1 & 1 & 2 & 1 \\
\hline Siderurgia e Metal. & 4 & - & 4 & 2 & 6 & 6 \\
\hline Telecomunic. & 2 & - & 2 & - & 4 & 3 \\
\hline Têxtil & 3 & 1 & 3 & 3 & 5 & 2 \\
\hline Transp. e Serviços & 1 & 1 & - & - & - & - \\
\hline Veículos e Peças & 2 & 2 & 2 & - & 3 & 3 \\
\hline Total & 36 & 16 & 34 & 12 & 53 & 31 \\
\hline
\end{tabular}


Nesta forma de avaliação, pode-se observar que, dentre os indicadores analisados, novamente, o indicador P/NPA apresenta melhor performance pós adesão. Contudo, há uma inversão de posições com relação aos indicadores ROA e ROE, sendo que, nesta verificação, 0 indicador de rentabilidade sobre ativos é o que obtém melhor colocação.

Diante dos resultados obtidos, esta pesquisa comprova os pressupostos teóricos apresentados por Steinberg (2003) e Carvalho (2003), a respeito da melhora do desempenho de mercado das companhias diferenciadas no mercado acionário por prática de governança corporativa. Os resultados obtidos, com relação ao indicador P/NPA, comprovam essa hipótese através do seu excelente desempenho frente aos demais indicadores analisados. Salientando que esse indicador, o qual trata diretamente da valorização das ações, tem sido o melhor com relação às análises Empresa versus Setor e Aumento versus Queda, após data do evento.

Além da melhora no preço de suas ações frente ao setor e em comparação com dados anteriores à migração, ainda existem mais fatores determinantes no processo de mudança de postura das companhias com relação à governança corporativa no mercado ações. Essa afirmação baseia-se em pesquisas desenvolvidas por Vieira; Mendes (2004) e Perobelli et al (2005), as quais comprovam que empresas reconhecidas por comporem níveis diferenciados de tratamento aos acionistas podem, também, contar com tratamento diferenciado para alocação de recursos e obtenção de ganhos junto aos custos de captação de tais recursos.

Contudo, esta pesquisa não se limita a simples visualização do comportamento das companhias frente ao advento da governança corporativa ou, como citado por Pound (apud STEINBERG, 2003), o surgimento de um novo conceito chamado "empresa governada". Por isso, tratou-se das avaliações num contexto estatístico mais aprofundado, dando espaço à aplicação de "Teste T" com as médias obtidas nas tabelas dos indicadores pertencentes às companhias listadas nos níveis de governança. Esta verificação tornou possível o direcionamento da pesquisa a um foco ainda mais contundente quanto à comprovação da veracidade dos resultados obtidos.

De acordo com as hipóteses formuladas ( $\mathrm{H} 0$ e $\mathrm{H} 1$, citadas na metodologia), procedeu-se a aplicação do teste para o indicador ROA. $O$ resultado obtido através da aplicação de teste t para este indicador resultou no valor $P=0,007140984$. Dessa forma, apoiado nas observações citadas por Barbetta (1999) e considerando o nível de significância $a=0,05$, o teste concluiu que H0 (o desempenho do indicador ROA das companhias não se altera após sua adesão aos níveis de governança corporativa) é falsa, pois $P$ é menor que $a$, denotando que houve aumento real da rentabilidade sobre ativos das companhias após sua adesão aos níveis de governança corporativa.

Considerando-se as mesmas hipóteses, aplicou-se a mesma seqüência de cálculos para 0 indicador ROE. Para a aplicação do teste para esse indicador calculou-se, primeiramente, as médias. 0 resultado obtido através da aplicação de teste t resultou no valor $P=0,00074691$. Dessa forma, considerando o nível de significância $a=0,05$, o teste concluiu que HO (o desempenho do indicador ROE das companhias não se altera após sua adesão aos níveis de governança corporativa) é falsa, pois $P$ é menor que $a$, denotando que houve aumento real da rentabilidade sobre patrimônio líquido das companhias após sua adesão aos níveis de governança corporativa.

$\mathrm{Na}$ aplicação do teste T para indicador P/NPA, procedeu-se de maneira semelhante aos demais indicadores. As médias previamente calculadas para os períodos anterior e posterior, utilizadas na aplicação do teste resultaram no valor $P=0,018373089$. Dessa forma, considerando o nível de significância $a=0,05$, o teste concluiu que H0 (o desempenho do indicador P/VPA das companhias não se altera após sua adesão aos níveis de governança corporativa) é falsa, pois $\mathrm{P}$ é menor que a, denotando que houve aumento real do preço das ações das companhias após sua adesão aos níveis de governança corporativa.

As conclusões - obtidas através da aplicação do Teste T para as análises dos desempenhos, tanto econômico quanto de mercado, das companhias listadas nos níveis de governança corporativa da 
BOVESPA - comprovam o real crescimento dos indicadores ROA, ROE e P/VPA. Dessa forma, observa-se que a prática de regras mais rígidas na divulgação de informações e no relacionamento com seus acionistas é vantajosa para a companhia. Pois, conforme comprovado nesta pesquisa, torna a companhia mais rentável, tanto no tocante aos retornos sobre ativos e patrimônio líquido, quanto na valorização do preço de suas ações no mercado acionário.

\section{CONCLUSÕES}

As teorias a respeito da inserção de valores relacionados à prática de governança corporativa nos diversos mercados acionários do mundo, tendem a definir que a aplicação de um modelo de governança reforça as possibilidades das companhias obterem maior crescimento econômico e de mercado, podendo agregar valor a sua imagem institucional. Conforme visto nesta pesquisa, não somente os mercados mais desenvolvidos do mundo preocupam-se com a implantação de um modelo de governança em sua bolsa de valores, as nações emergentes também estão começando a visionar ideais relacionados à adequação de seu mercado de ações aos padrões de transparência vigentes em países, nos quais a cultura de desenvolvimento das organizações passa por etapas de aprimoramento constante quanto às relações com investidores.

Se a implantação, por determinado mercado, de níveis que diferenciem das demais, as empresas dispostas a desenvolverem práticas que aprimorem sua interação com os stakeholders, for percebida como algo que visa desenvolver a ética e proporcionar crescimento da economia de uma nação, certamente agregará valor às companhias envolvidas e poderá aumentar o volume de negócios do mercado, principalmente, pelo fato de as ações negociadas estarem atreladas a padrões sérios de transparência e respeito a quaisquer investidores.

Os resultados obtidos nesta pesquisa não diferem da teoria existente e comprovam que as companhias que optaram pelo cumprimento de regras, além das habitualmente exigidas, tornaram-se rentáveis. As análises de todos os indicadores comprovam que, de modo geral, as empresas obtêm maior o crescimento econômico e de mercado depois de inseridas no sistema de listagem utilizado para classificar as companhias dispostas a promover relações mais igualitárias, transparência e responsabilidade na prestação de contas. Embora possa ser considerada recente, no Brasil, a história da governança corporativa já produz resultados positivos no que se refere à melhora de sua imagem perante os mercados com sistema de governança mais desenvolvido. Mesmo havendo adversidades para implantação de um sistema amplo e de visão holística no mercado acionário brasileiro, o país possui um número considerável de companhias participantes do sistema de listagem instituído pela BOVESPA para prática de regras mais abrangentes no tocante à governança corporativa. Esse aspecto poderá trazer um futuro promissor para as companhias nacionais com ações na bolsa e para 0 próprio mercado, tendo em vista o crescente número de empresas que vem aderindo ao sistema de listagem desde 0 início desta pesquisa.

Não tão distante da perspectiva anteriormente abordada, pode-se citar o envolvimento de vários órgãos no processo de aprimoramento do mercado de ações, adequando-o a padrões amplos de governança corporativa. Entidades, como IBGC, CVM e BOVESPA, interagem com o mercado acionário, proporcionando a este condições para formação de um sistema de governança sólido e produtivo. Com perspectivas de promover um futuro promissor no que diz respeito ao aumento do número de companhias dispostas a abrirem o capital e negociarem suas ações em um mercado evoluído e compatível com os padrões internacionais de responsabilidade para com o público investidor. 


\section{REFERÊNCIAS}

ALBERTON, Anete. Meio ambiente e desempenho econômico-financeiro: o impacto da ISO 14001 nas empresas brasileiras. Florianópolis, 2003, 307p. Tese (Doutorado em Engenharia da Produção) Universidade Federal de Santa Catarina, 2003.

ANDRADE, Adriana; ROSSETI, José P. Governança corporativa. São Paulo: Atlas, 2004.

BOVESPA. Níveis diferenciados de governança corporativa. BOVESPA, 2002. Disponível em: $<$ <ww.bovespa.com.br>. Acesso em: 26 julho 2005.

BOVESPA. Novo Mercado e Níveis de governança corporativa. BOVESPA, 2005. Disponível em: <www.bovespa.com.br>. Acesso em: 30 julho 2005.

CANUTO, Otaviano. Convergência corporativa: diminuem as diferenças no financiamento e na governança corporativa nas economias avançadas. Jornal O Estado de São Paulo, São Paulo, out. 2000. Disponível em: < www.eco.unicamp.br>. Acesso em: 25 setembro 2005.

CARVALHO, Antônio G. Efeitos da migração para os níveis de governança da BOVESPA. 2003. Disponível em < www.econ.puc-rio.br >. Acesso em 30 setembro 2005.

CICOGNA, Maria P. V.; VALLE, Maurício R. do; TONETO JR, Rudinei. O impacto da adesão a padrões mais elevados de governança sobre o financiamento empresarial. In: XXIX ENANPAD. Anais...

Brasília. 2005.

CVM. Governança Corporativa - A Cartilha da CVM. CVM, 2002. Disponível em: <www.cvm.org.br>. Acesso em: 08 agosto 2005.

HALLQVIST, Herbert. O "Rambo" empresarial está com os dias contados. In: STEINBERG, Herbert. (Org.). A dimensão humana da governança corporativa. São Paulo: Editora Gente, 2003. Cap.1, p. 15-53.

IBGC. Código das melhores práticas de governança corporativa. IBGC, 2005. Disponível em: <www.ibgc.org.br>. Acesso em: 30 junho 2005.

LAMB, Roberto. Governança corporativa; arena e contexto. 2002. UFRGS. Disponível em: $<$ <ww.pucrs.br>. Acesso em: 25 julho 2005.

LEAL, Ricardo P.C.; SILVA, André L. C. da; VALADARES, Sílvia M. Estrutura de controle das companhias brasileiras de capital aberto. RAC - Revista de Administração Contemporânea, São Paulo, v.6, n.1, p.07-18, jan/abr. 2002.

LETHBRIDGE, Eric. Governança corporativa. 2004. Disponível em: < www.bndes.org.br >. Acesso em: 01 agosto 2005.

LIMA, João B. N. de; TERRA, Paulo R. S. Governança corporativa e reação do mercado de capitais às informações financeiras. In: XXVIII ENANPAD. Anais... Curitiba. 2004.

LUQUE, Carlos A. Prefácio. In: SROUR, Robert H. (Org.). Ética empresarial. Rio de Janeiro: Campus, 2000. Prefácio, p. 9-11. 
LUSTOSA, Eliane Aleixo. Como agregar valor às ações na visão dos investidores. ANIMEC, 2002. Disponível em: <www.animec.com.br>. Acesso em: 31 agosto 2005.

MARCON, Rosilene. Responsabilidade social corporativa, vantagem competitiva e desempenho financeiro. The business association of latin american studies - Balas. São Paulo, 2003. Anais... BALAS.

NAIDITCH, Suzana. O Brasil descobre a bolsa. Revista Exame. São Paulo, abr. 2006. Disponível em: < www.exame.com.br >. Acesso em: 02 Abril 2006.

OKIMURA, Rodrigo T.; SILVEIRA, Alexandre Di M.; ROCHA, Keyler C. Estrutura de propriedade e desempenho corporativo no Brasil. 2004. In: XXVIII ENANPAD. Anais... Curitiba. 2004.

OLIVEIRA, Jaildo L. de; SILVA, César A. T. A governança corporativa no sistema financeiro nacional. BCB, Brasília, 2004. Disponível em: <www4.bcb.gov.br>. Acesso em: 20 julho 2005.

PARREIRAS, Fernando S. Impacto da migração para os níveis de governança corporativa da BOVESPA: uma análise do risco. FACE/UFMG, Belo Horizonte, 2003.

PEROBELLI, Fernanda F. C. et al. Investigação dos fatores determinantes da estrutura de capital e da governança corporativa: um enfoque abordando a questão da endogeneidade. In: XXIX ENANPAD. Anais... Brasília, 2005.

RABELO, Flávio; SILVEIRA, José M. da. Estruturas de governança e governança corporativa: avançando na direção da integração entre as dimensões competitivas e financeiras. IE/UNICAMP, Campinas, 1999. Disponível em: <www.eco.unicamp.br>. Acesso em: 18 julho 2005.

RODRIGUEZ, Gregório M. A governança tem que ser exercida de fato. Revista Relações com Investidores. 2005.

RODRIGUEZ, Gregório M. Efeitos da migração para os níveis de governança da BOVESPA. ANIMEC, 2003. Disponível em: <www.animec.com.br>. Acesso em: 31 agosto 2005.

ROGERS, Pablo; RIBEIRO, Karém C. de S. Governança corporativa e limites para o desenvolvimento do mercado de capitais nacional: análise do risco Brasil. In: XXVII ENANPAD. Anais... Atibaia, 2003.

SANVICENTE, A.Z. Administração financeira. São Paulo: Atlas, 1983.

SETÚBAL, Alfredo. Governança corporativa e os limites da transparência: a experiência do Itaú. IBGC, 2005. Disponível em: < www.ibgc.org.br >. Acesso em: 08 outubro 2005.

SIFFERT FILHO, Nelson. Governança corporativa: padrões internacionais e evidências empíricas nos anos 90. Revista do BNDES, 2002. Disponível em: <www.bndes.gov.br>. Acesso em: 01 agosto 2005.

\section{SILVEIRA, Alexandre Di M.da. Governança corporativa, desempenho e valor da}

empresa no Brasil. São Paulo, 2002. 152f. Dissertação (Mestrado em Administração) - Faculdade de Economia, Administração e Contabilidade, 2002. Disponível em:< www.teses.usp.br>. Acesso em: 30 julho 2005. 
SILVEIRA, Alexandre Di M.da; Governança corporativa e estrutura de propriedade: determinantes e relação com o desempenho das empresas no Brasil. 2004. 254f. Tese (Doutorado) - FEA, USP, São Paulo, 2004. Disponível em: <www.teses.usp.br>. Acesso em: 30 julho 2005.

SROUR, Gabriel. Práticas diferenciadas de governança corporativa: um estudo sobre a conduta e a performance das firmas brasileiras. 2002. Tese (Mestrado) - PUC, Rio de Janeiro, 2002.

Disponível em: <www.econ.puc-rio.br>. Acesso em: 30 agosto 2005.

SROUR, Robert H. Ética empresarial. Rio de Janeiro, Campus: 2000.

STEINBERG, Herbert. et al. A dimensão humana da governança corporativa. São Paulo: Editora Gente, 2003.

VIEIRA, Solange P.; MENDES, André G. S. T. Governança corporativa: uma análise de sua evolução e impactos no mercado de capitais brasileiro. Revista do BNDES. Rio e Janeiro. V.11, n.22, p. 103-122, dez/2004.

COMPARATIVE STUDY BETWEEN ECONOMIC AND MARKET PERFORMANCE: THE CASE OF COMPANIES INCLUDED IN THE LEVELS OF CORPORATE GOVERNANCE

\begin{abstract}
This study had the objective to investigate the economical and of market performance of the Brazilian companies before and after the inclusion in the levels of corporate governance proposed by BOVESPA. The study period understood the years from 1999 to 2004, where the ratios were collected: Return on Equity, Return on Assets and Price-to-Book. The results showed good acting of the indicator P/VPA, due his/her the best performance of the Price-to-book. This conclusion is obtained through the evaluation of the behavior of the ratios, confronting the periods before and after event, as well as when being drawn comparative among the acting of the companies in relationship economic sector of performance. The comparative general of the ratios regarding the performance of the participant companies of the system of listing of BOVESPA it indicated that the great majority reached improvement of the performance, in other words, they presented larger return on assets and equity, as well as in the value of their actions after they migrate for some of the levels of corporate governance
\end{abstract}

Key words: Economic performance. Bovespa. Corporate Governance.

Submissão: março de 2006 Aceite: outubro de 2006 